\title{
Effects of Anti-Browning Pretreatments on Browning of Banana Pulp
}

\author{
Simran Arora*, Saleem Siddiqui, Rakesh Gehlot and Naseer Ahmed \\ Centre of Food Science and Technology, CCS Haryana Agriculture University, \\ Hisar, Haryana, India \\ *Corresponding author
}

\begin{abstract}
A B S T R A C T
The present investigation was carried to examine the effects of different anti-browning agents on browning and sensory quality of extracted banana pulp. The banana fruit from

Keywords

Banana pulp, Antibrowning pretreatments, Browning index, Sensory evaluation

Article Info

Accepted: 04 March 2018 Available Online: 10 April 2018 ripe and over-ripe stages were separately peeled, sliced and pulped using different pretreatments such as blanching in water (at $95^{\circ} \mathrm{C}$ for $2 \mathrm{~min}$ ), potassium meta-bisulphite $(0.1 \%)$, potassium meta-bisulphite $(0.2 \%)$, citric acid $(1 \%)$, citric acid $(2 \%)$, ascorbic acid ( $1 \%$ ), $1 \%$ citric acid and $0.5 \%$ cysteine, $1 \%$ citric acid and $0.5 \%$ calcium chloride, $1 \%$ citric acid and $1 \%$ ascorbic acid and $0.5 \%$ cysteine. Sliced banana were mixed with small amount of water containing anti-browning agent and blended in mixer for pulping. Pretreated banana pulp from ripe and over-ripe fruit was analyzed for browning index and sensory (color and appearance, taste, aroma and overall acceptability) quality. Among the various treatments tried for preventing browning, the pre-treatment of the pulp with potassium metabisulphite (KMS) at the concentration of 0.1 and $0.2 \%$ was found to be the most effective treatment, where both of its concentrations were equally effective in controlling browning in ripe and over-ripe banana pulp. The effect of anti-browning pretreatments were similar for ripe and over-ripe banana pulp, however the control of browning was more in ripe pulp than from over-ripe banana pulp.
\end{abstract}

\section{Introduction}

Fruits and vegetables are indispensable constituents of human diet, as they provide substantial quantities of functional components, especially vitamins, sugars, minerals, fiber and phytochemicals. Regular consumption of fruits and vegetables lessens the risk of cancer, heart disease, premature ageing, stress and fatigue chiefly due to the integrated action of oxygen radical scavengers such as $\beta$ - carotene, ascorbic acid, polyphenols with calcium and dietary fibers present in them (Sindumathi et al., 2013). India is the second largest producer of the fruits $(90.534$ million tons) and vegetables (166.467 million tons) in the world (National Horticulture Board, 2015-16) after China. India produces a wide range of fruits and vegetables due to its diverse agro-climatic conditions.

Banana (Musa paradisiaca L.), belongs to Musaceae family. It is one of the most widely cultivated fruits in tropical countries, being the second largest produced fruit after citrus with 108 million tons in 2013, contributing about $16 \%$ of the world's total fruit production (FAO, 2016). India is the largest producer of 
banana with an annual production of 30.08 million tons from an area of 0.88 million ha, contributing to $27 \%$ of the world's banana production (National Horticulture Board, 2016). In India, Tamil Nadu is the leading producer state for banana, followed by Maharashtra. 'Dwarf Cavendish' and 'Robusta' are the most widespread banana varieties commonly grown in India and are the main stays of Indian banana industry for both internal and export trades (Tapre and Jain, 2012).

Banana is one of the cheapest, delicious and most nourishing of all fruits. It is preferred by people of all ages. It has also several medicinal properties. Many in vitro studies, animal model studies and clinical studies showed that various parts of banana act as food medicines for treatment of diseases like diabetes, hypertension, cancer, ulcers, diarrhoea, urolithiasis, Alzheimer's and infections (Jyothirmayi and Rao, 2015).

Banana is a climacteric fruit and after harvest it exhibits a respiratory peak during natural ripening at $20^{\circ} \mathrm{C}$. The quality of the fresh banana decreases drastically after harvesting as a result of deterioration in fruits' colour, flavour and texture. It has post-harvest shelf life of only 2-3 days during summer season. Hence, it has always being considered a problem fruit.

Exploring possibilities of converting banana into value added products is one of the approaches to solve this problem. Problem with processing of banana pulp is its enzymatic browning. It undergoes rapid enzymatic browning upon exposure to oxygen as a result of cellular disruption during peeling, slicing and pulping operations (Macdonald and Schaschke, 2000). Polyphenol oxidase is responsible for enzymatic browning of many edible plant products, especially of fruits and vegetables during processing. Several methods including addition of anti-browning agents and thermal processing have been used to inhibit enzymatic browning (Sun et al., 2002). Antibrowning agents such as tartaric acid, ascorbic acid, calcium chloride, cysteine and citric acid are some of the generally regarded as safe (GRAS) chemicals that have potential for browning inhibition and control of enzymatic browning of fresh and vacuum fried slices of banana (Apintanapong et al., 2007).

\section{Materials and Methods}

The present study was carried out in Centre of Food Science and Technology, CCS HAU, Hisar during the year 2016-17. The study was conducted to identify the best anti-browning agent to control the browning of banana pulp during processing.

\section{Procurement of materials}

Banana fruit was procured from local orchards/ market, Hisar during 2016-2017.

\section{Reagents}

The chemicals used in investigation were analytical grade reagents (A.R.) from standard suppliers e.g. B.D.H., C.D.H., S.D. Fine Chemicals, Sisco Research Lab., etc.

\section{Treatment and processing of banana}

Ripe fruits of banana were procured from local market and divided into two lots. One lot was processed and other was allowed to ripe further to over-ripe stage under controlled condition and then processed.

\section{Sorting, peeling and slicing}

Healthy and diseased free ripe and over-ripe banana were separately sorted, peeled and sliced using stainless steel knives. 


\section{Anti-browning pre-treatments and pulp extraction}

Before pulp extraction banana slices were subjected to anti-browning pre-treatments to control enzymatic browning. The pretreatments tried were blanching in water (at $95^{\circ} \mathrm{C}$ for $2 \mathrm{~min}$ ), potassium meta-bisulphite $(0.1 \%$ and $0.2 \%)$, citric acid (1\% and $2 \%)$, ascorbic acid (1\%), $1 \%$ citric acid $+0.5 \%$ Cysteine, $1 \%$ citric acid $+0.5 \%$ calcium chloride, $1 \%$ Citric acid $+1 \%$ ascorbic acid + $0.5 \%$ cysteine.

Sliced banana were mixed with small amount of water containing anti-browning agent and blended in mixer. The treatments were taken in three replicates. The procedure adopted for pulp extraction and anti-browning pretreatments is presented in Figure 1.

Extracted pulp from ripe and over-ripe fruits with anti-browning agent was passed from homogenizer, separately filled in polypropylene jars and stored in deep freezer for six days to analyze its browning index.

\section{Evaluation of effectiveness of anti-browning treatments}

Effectiveness of different anti-browning pretreatment on banana pulp from ripe and over-ripe stages were evaluated by measuring their browning index and sensory quality.

\section{Browning index}

Five gram of sample was macerated with 25 $\mathrm{ml}$ of 60 per cent aqueous ethyl alcohol and kept it overnight in the covered condition in dark. On the next day, sample was filtered to obtained clear solution. Absorbance of clear solution was taken at $440 \mathrm{~nm}$ using 60 per cent aqueous ethyl alcohol as blank with UVVIS spectrophotometer. Browning index (A at $440 \mathrm{~nm}$ ) was expressed as absorbance value.

\section{Sensory evaluation ( 9 point hedonic scale)}

Sensory evaluation of treated banana pulp from ripe and over-ripe fruit was evaluated by a panel of six judges up to 6 days using the 9point hedonic scale as described by Ranganna (2014). Beaker containing $20 \mathrm{ml}$ of the banana pulp was presented to the judges. It was evaluated for colour and appearance, taste, aroma and overall acceptability. The overall acceptability of RTS drink was calculated on the basis of mean scores obtained from all the sensory parameters. The samples with mean scores of 6 and above out of 9 were considered acceptable.

\section{Statistical analysis}

The data in the present investigation were subjected to analysis of variance (ANOVA) technique and analyzed according to two factorial completely randomized design (CRD). The critical difference (CD) value at 5 per cent level was used for making comparison among different treatments. Software OP stat (www.hau.ernet.in) was used to analyze the experimental results statistically.

\section{Results and Discussion}

\section{Browning index}

The pulp of banana fruit is highly susceptible to enzymatic browning when it comes in contact with air. Browning reaction is due to enzymatic oxidation of dopamine by polyphenol oxidase leading to the production of brown pigments (Ranveer et al., 2010). In the present investigation, the data in Table 1 reveal the effect of different anti-browning pretreatments on browning of ripe and overripe banana pulp. It was observed from the data that there was progressive increase in browning of banana pulp with increasing storage period. In control, the browning at 0- 
day was 0.185 and 0.211 that increased to 0.213 and 0.226 in ripe and over-ripe banana pulp respectively by 6 days of storage. There was significant reduction in browning by various treatments.

The browning was found maximum in control that increased during storage. There was significant reduction in browning by various treatments. The best pretreatment showing maximum reduction in browning was potassium metabisulphite (KMS), where both of its concentrations ( 0.1 and $0.2 \%)$ were equally effective in both ripe and over-ripe banana fruit pulp.

The interaction between treatments and storage was found to be significant. Similarly, Canu et al., (1990) reported successful prevention of browning in banana by inactivation of enzyme polyphenol oxidase by addition of potassium metabisulphite.

Sims et al., (1994) studied the effect of bisulphite and ascorbic acid treatments on the color and polyphenol oxidase activity of clarified juice from ripe bananas and observed that the sulfited juice had the lightest color and least amount of browning. Ruthra et al., (2014) studied the effect of pretreatment on minimally processed banana with citric acid (CA), ascorbic acid (AA) and potassium metabisulphite (KMS) with varying concentration and their combinations. They observed that KMS at $0.2 \%$ and combination of KMS and AA were most effective in control of browning. Siriwardana et al., (2015) reported that sodium metabisulphite most effectively controlled the browning of sliced banana. The control of browning could be due to oxidative nature of sulphites and their derivatives (sulfur dioxide, sulphite, bisulphite and metabisulphite) which act as color stabilizer. It has been reported that potassium and sodium sulphites, prevent enzymatic browning by reducing o-quinones to colorless diphenol (Grotheer et al., 2008) or by reacting irreversibly with o-quinones to form stable colorless products (Marshall et al., 2000).

\section{Sensory evaluation}

The data regarding the effect of different antibrowning pretreatments on sensory quality of ripe and over-ripe banana pulp is presented in Table 2.

It was observed from the data that potassium metabisulphite $(0.1$ and $0.2 \%)$ treated banana pulp from ripe and over-ripe fruit ranked better overall acceptability score than other. Sensory score for color and appearance was maximum for banana pulp with potassium metabisulphite at the concentration of 0.1 and $0.2 \%$, followed by ascorbic acid, citric acid + cysteine, citric acid $+\mathrm{CaCl}_{2}$, citric acid + ascorbic acid +cysteine while minimum was recorded for control sample.

The highest score with KMS is due to their effectiveness in controlling the browning and maintained the original color of banana pulp (Plate 1). Result of present investigation was in conformity with the findings of Sakhale et al., (2012) who reported that treatment of mango pulp with KMS retained original color and appearance than sodium benzoate treated pulp. Similarly Durrani et al., (2011) reported that mango pulp stored with KMS treatment retained overall color stability during 90 days of storage period than potassium sorbate, ascorbic acid and sodium benzoate.

Similar to color and appearance score, taste score was better for banana pulp with potassium metabisulphite followed by control. The treatment of banana pulp with citric acid and ascorbic acid increase the acidity and cysteine, $\mathrm{CaCl}_{2}$ impart unpleasant taste to the banana pulp which was not liked by panelist. 
Fig.1 Flow sheet for extraction of banana pulp

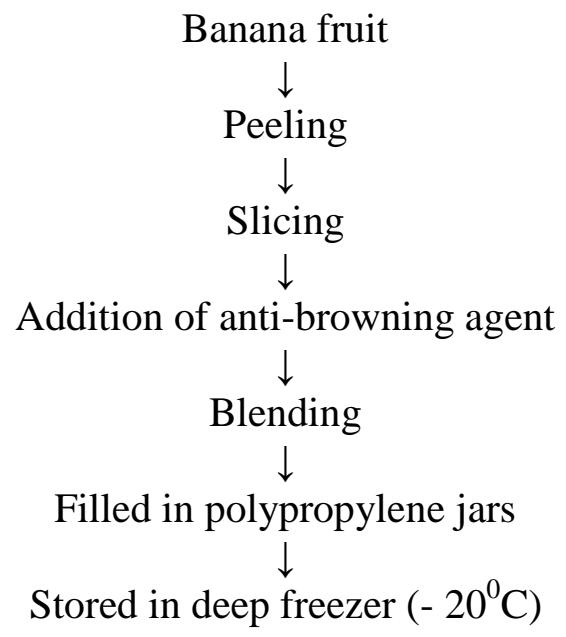

Table.1 Effect of anti-browning pre-treatments on browning (O.D. at $440 \mathrm{~nm}$ ) of ripe and overripe (values in parentheses) banana pulp

\begin{tabular}{|l|}
\hline Treatments \\
\hline Control \\
\hline Blanched \\
\hline KMS $(0.1 \%)$ \\
\hline KMS $(0.2 \%)$ \\
\hline Citric acid (1 \%) \\
\hline Citric acid $(2 \%)$ \\
\hline Ascorbic acid $(1 \%)$ \\
\hline $1 \%$ Citric acid $+0.5 \% \mathrm{Cysteine}^{\circ}$ \\
\hline $1 \%$ Citric acid $+\mathbf{0 . 5} \% \mathrm{CaCl}_{2}$ \\
\hline $1 \%$ Citric acid $+1 \% \mathrm{Ascorbic}_{\text {acid }+0.5 \%}$ Cysteine \\
\hline Mean \\
\hline C.D. at $5 \%$ \\
\hline
\end{tabular}

\begin{tabular}{|c|c|c|c|}
\hline \multicolumn{4}{|c}{ Period of storage (days) } \\
\hline $0.185(0.211)$ & $0.192(0.221)$ & $0.213(0.226)$ & Mean \\
\hline $0.047(0.070)$ & $0.059(0.079)$ & $0.074(0.082)$ & $\mathbf{0 . 1 9 7}(\mathbf{0 . 2 1 9})$ \\
\hline $0.028(0.032)$ & $0.029(0.032)$ & $0.030(0.034)$ & $\mathbf{0 . 0 2 9}(\mathbf{0 . 0 3 2})$ \\
\hline $0.025(0.029)$ & $0.026(0.031)$ & $0.026(0.031)$ & $\mathbf{0 . 0 2 6}(\mathbf{0 . 0 3 1})$ \\
\hline $0.043(0.058)$ & $0.058(0.065)$ & $0.062(0.069)$ & $\mathbf{0 . 0 5 4}(\mathbf{0 . 0 6 4})$ \\
\hline $0.039(0.056)$ & $0.049(0.063)$ & $0.054(0.063)$ & $\mathbf{0 . 0 4 7}(\mathbf{0 . 0 6 1})$ \\
\hline $0.081(0.091)$ & $0.095(0.098)$ & $0.103(0.112)$ & $\mathbf{0 . 0 9 3}(\mathbf{0 . 1 0 3})$ \\
\hline $0.038(0.051)$ & $0.040(0.057)$ & $0.045(0.064)$ & $\mathbf{0 . 0 4 1}(\mathbf{0 . 0 5 7})$ \\
\hline $0.042(0.056)$ & $0.045(0.062)$ & $0.066(0.073)$ & $\mathbf{0 . 0 5 1}(\mathbf{0 . 0 6 4})$ \\
\hline $0.114(0.129)$ & $0.123(0.132)$ & $0.126(0.133)$ & $\mathbf{0 . 1 2 1}(\mathbf{0 . 1 3 1})$ \\
\hline $\mathbf{0 . 0 6 4}(\mathbf{0 . 0 7 8})$ & $\mathbf{0 . 0 7 2}(\mathbf{0 . 0 8 4})$ & $\mathbf{0 . 0 8 1}(\mathbf{0 . 0 8 9})$ & \\
\hline
\end{tabular}

Table. 2 Effect of anti-browning pre-treatments on sensory quality (9-point hedonic scale) of banana pulp from ripe and over-ripe (values in parentheses) fruit

\begin{tabular}{|l|}
\hline Treatments \\
\hline Control \\
\hline Blanched \\
\hline KMS $(0.1 \%)$ \\
\hline KMS $(0.2 \%)$ \\
\hline Citric acid $(1 \%)$ \\
\hline Citric acid $(2 \%)$ \\
\hline Ascorbic acid $(1 \%)$ \\
\hline $1 \%$ Citric acid $+0.5 \% \mathrm{Cysteine}^{\circ} \% \mathrm{CaCl}_{2}$ \\
\hline $1 \%$ Citric acid $+0.5 \%$ Citric acid $+1 \% \mathrm{Ascorbic}$ acid $+0.5 \%$ \\
\hline $1 \%$ Cysteine \\
\hline
\end{tabular}

\begin{tabular}{|c|c|c|c|}
\hline \multicolumn{4}{|c|}{ Sensory score } \\
\hline Color and appearance & Taste & Aroma & Overall Acceptability \\
\hline $2.0(2.0)$ & $7.0(7.0)$ & $7.5(8.0)$ & $5.5(5.7)$ \\
\hline $6.0(4.0)$ & $5.0(5.0)$ & $5.0(5.0)$ & $5.3(4.7)$ \\
\hline $8.0(7.5)$ & $7.5(8.0)$ & $7.0(7.0)$ & $7.5(7.5)$ \\
\hline $8.0(7.5)$ & $7.5(8.0)$ & $7.0(7.0)$ & $7.5(7.5)$ \\
\hline $6.0(4.0)$ & $4.0(4.0)$ & $4.0(5.0)$ & $4.7(4.3)$ \\
\hline $6.0(5.0)$ & $4.0(4.0)$ & $4.0(5.0)$ & $4.7(4.7)$ \\
\hline $6.5(6.0)$ & $5.0(5.0)$ & $5.5(5.5)$ & $5.7(5.5)$ \\
\hline $7.0(7.0)$ & $4.0(4.0)$ & $4.0(4.0)$ & $5.0(5.0)$ \\
\hline $7.0(7.0)$ & $4.0(4.0)$ & $5.0(5.0)$ & $5.3(5.3)$ \\
\hline $7.0(7.0)$ & $4.0(4.0)$ & $4.0(4.0)$ & $5.0(5.0)$ \\
\hline
\end{tabular}


Plate.1 Effect of different pretreatments on non-enzymatic browning of pulp from (A) ripe and (B) over-ripe banana

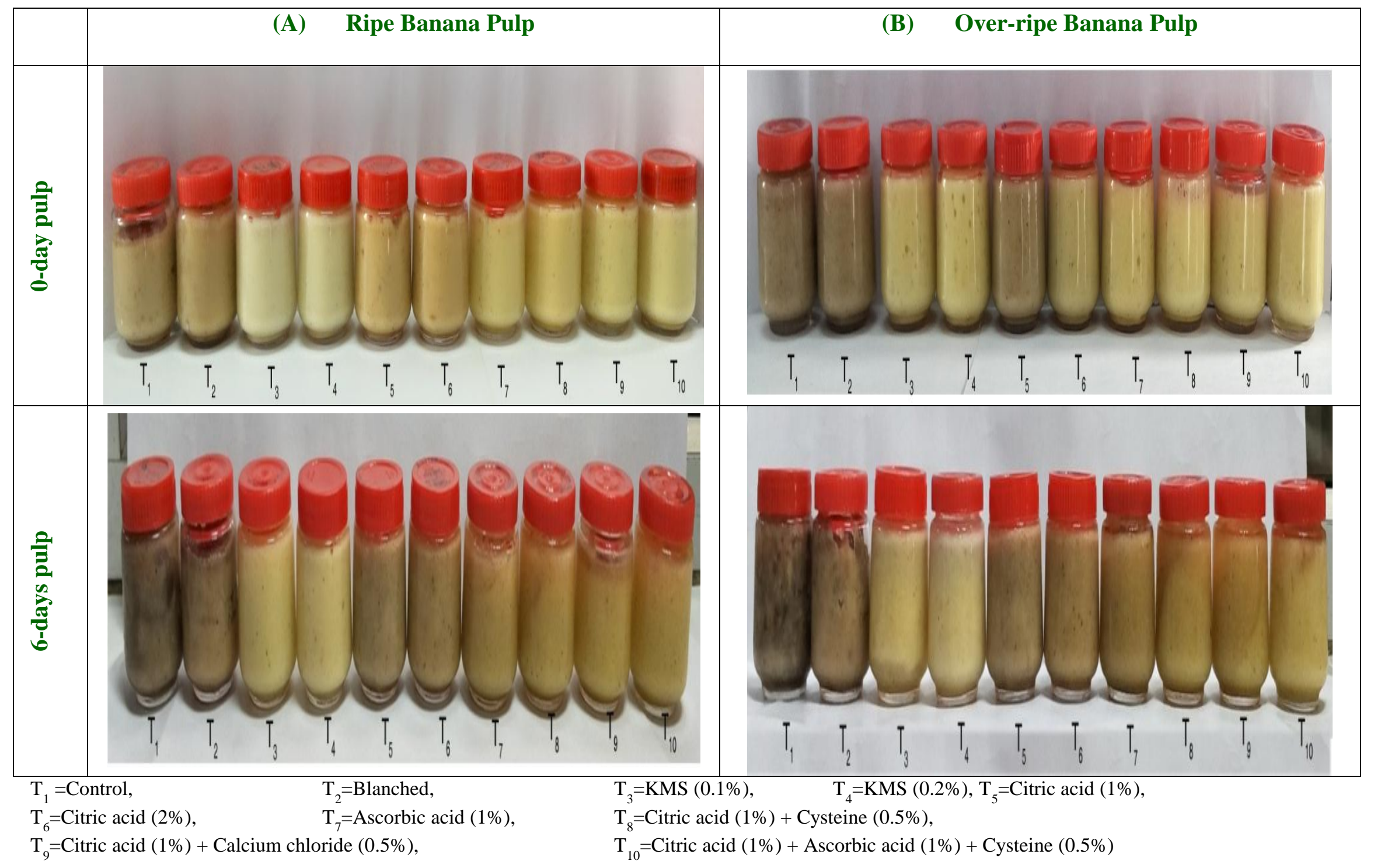


Result of present investigation are in conformity with the findings of Luna-Guzman and Barrett (2000) who reported that treatment of fresh-cut cantaloupe with $\mathrm{CaCl}_{2}$ gives bitter taste than untreated samples or those dipped in calcium lactate. Durrani et al., (2011) reported that KMS treated mango pulp scored maximum for taste than potassium sorbate, ascorbic acid and sodium benzoate.

Sensory score for aroma was highest for control followed by potassium metabisulphite treatment. KMS treated banana pulp ranked slightly less than control because of pungent smell of sulfite when sniffed immediately after processing but it lost after 4-5 hours of pulping. The other chemical treatments (citric acid, ascorbic acid, cysteine and $\mathrm{CaCl}_{2}$ ) imparts unpleasant aroma to pulp of banana. The result of present investigation are in accordance with the findings of Queiroz et al., 2008 who reported that cysteine produces an undesirable odour, limiting its use in food processing. Hashmi et al., (2007) reported that KMS treated mango pulp scored maximum for taste than potassium sorbate and sodium benzoate treated. The effect of anti-browning pre-treatments on sensory quality were similar for ripe and over-ripe banana pulp, however the sensory score was more in ripe pulp than from over-ripe banana pulp.

It can be concluded from the results of the present study that the pre-treatment of the pulp with potassium metabisulphite (KMS) at the concentration of 0.1 and $0.2 \%$ was found to be the most effective treatment, where both of its concentrations were equally effective in controlling non-browning in ripe and overripe banana pulp. Sensory score (Color and appearance, taste and overall acceptability) was also higher for banana pulp treated with potassium metabisulphite than other chemical treatments. By controlling the browning of banana pulp, we can reduce the spoilage, stored it for months and utilize for processing into various products.

\section{References}

Apintanapong, M., Cheachumluang, K., Suansawan, P. and Thongprasert, N. (2007). Effect of anti-browning agents on banana slices and vacuum-fried slices.

Journal of Food Agriculture and Environment, 5(3/4), 151.

Arias, E., González, J., Oria, R. and Lopez- Buesa, P. (2007). Ascorbic Acid and 4- Hexylresorcinol Effects on Pear PPO and PPO Catalyzed Browning Reaction. Journal of food science, 72(8).

Cano, P., Marín, M.A. and Fúster, C. (1990). Effects of some thermal treatments on polyphenoloxidase and peroxidase activities of banana (Musa cavendishii, varenana). Journal of the Science of Food and Agriculture, 51(2), 223-231.

Durrani, Y., Zeb, A., Ayub, M., Ullah, W. and Muhammad, A. (2011). Sensory evaluation of mango (Chaunsa) pulp preserved with addition of selected chemical preservatives and antioxidant during storage. Sarhad J. Agric, 27(3), 471-475.

FAO (2016). Food and Agriculture Organization of the United Nations. Statistics web site http://www.fao.org

Grotheer, P., Marshall, M. and Simonne, A. (2008). Sulphites: separating fact from fiction. Department of Family, Youth and Community Sciences, Florida Cooperative Extension Services, Institute of Food Agricultural Science, University of Florida, http://edis.ifas.ufl.edu/FY731

Hashmi, M.S., Alam, S., Riaz, A. and Shah, A.S. (2007). Studies on microbial and sensory quality of mango pulp storage with chemical preservatives. Pakistan Journal of Nutrition, 6(1), 85-88.

Jyothirmayi, N. and Rao, N.M. (2015). Banana medicinal uses. Journal of 
Medical Science Technology, 4(2), 152160.

Luna-Guzman, I. and Barrett, D.M. (2000). Comparison of calcium chloride and calcium lactate effectiveness in maintaining shelf stability and quality of fresh-cut cantaloupe. Postharvest in Biology and Technology, 19, 61-72.

MacDonald, L. and Schaschke, C.J. (2000). Combined effect of high pressure, temperature and holding time on polyphenoloxidase and peroxidase activity in banana (Musa acuminata). Journal of the Science of Food and Agriculture, 80, 719-724.

Marshall, M.R.; Kim, J. and Wei, C. (2000). Enzymatic browning in Fruits, Vegetables and Sea foods. FAO: Rome, Italy, 2000.

National Horticulture Board. (2016). Horticultural statistics at a glance. Oxford University Press, New Delhi, p 199.

Queiroz, C., Mendes Lopes, M.L., Fialho, E. and Valente-Mesquita, V.L. (2008). Polyphenol oxidase: characteristics and mechanisms of browning control. Food reviews international, 24(4), 361-375.

Ranganna, S. (2014). Handbook of analysis and quality control for fruit and vegetable products. Tata McGraw Hills Publishing Co. Ltd., New Delhi.

Ranveer, R.C., Pawar, V.N., Sakhale, B.K. and Sahoo A.K. (2010). Effect of storage conditions on the residual PPO enzyme activity of raisins. International Journal of Agricultural Science, 61, 61-64.

Ruthra Priya, J.S., Ravindra, N. and Dayanand, P. (2014). Studies on pretreatment of minimally processed banana central core. International Journal of Research in Science, 1(2), 110-116.

Sakhale, B.K., Pawar, V.N. and Ranveer, R.C. (2012). Studies on effect of chemical preservatives on keeping quality of Kesar mango pulp. Open Access Scientific Reports, 1(3).

Sims, C.A. and Bates, R.P. (1994). Challenges to processing tropical fruit juices: banana as an example. In Proceedings-Florida State Horticultural Society, 107, 315-319.

Sindumathi, G. and Premalatha. M.R. (2013). Development and storage studies of naturally flavored papaya-pineapple blended ready-to-serve (RTS) beverages. International Journal of Science and Research, 4(2), 856-860.

Siriwardana, H., Abeywickrama, K. and Kannangara, S. (2015). Effect of pretreatments on quality of minimally processed cooking banana variety alukesel (Musa acuminate $\times$ Musa balbisiana, ABB group). Journal of Agricultural Sciences, 10(1), 11-20.

Sun, N., Lee, S. and Song, K.B. (2002). Effect of high-pressure treatment on the molecular properties of mushroom polyphenol oxidase. LWT- Food Science and Technology, 35, 315-318.

Tapre, A.R. and Jain, R.K. (2012). Study of advanced maturity stages of banana. International Journal of Advance Engineering Research Studies, 1, 272274.

\section{How to cite this article:}

Simran Arora, Saleem Siddiqui, Rakesh Gehlot and Naseer Ahmed. 2018. Effects of AntiBrowning Pretreatments on Browning of Banana Pulp. Int.J.Curr.Microbiol.App.Sci. 7(04): 242-249. doi: https://doi.org/10.20546/ijcmas.2018.704.027 